\title{
Absorptive Capacity and Benefits from FDI: Evidence from Chinese Manufactured Exports
}

\author{
Yingkai Tang and Kevin H. Zhang*
}

\begin{abstract}
China's global export rank rose from the $32^{\text {nd }}$ in 1978 to the $1^{\text {st }}$ in 2009 , and in the same period China had been a top recipient of foreign direct investment (FDI) in the world. Does large FDI inflow automatically lead to the export boom? Or is it a must for China to have certain absorptive capacity (AC) given FDI? This work investigates how manufacturing exports (MX) are affected by the AC-FDI interaction. MX performance is assessed by three indicators: export capacity, export intensity, and export quality. AC is defined as a hostcountry's ability to capture potential benefits from FDI, and such ability is proxied by government FDI policy, human capital, R\&D, and infrastructure. Estimates are conducted with the data on 21 manufacturing sectors for 31 regions over 8 years (2005-2012). We find that (a) AC is necessary condition for China to benefit from FDI in MX, and contributions of FDI alone to MX are limited; (b) China's strong AC largely comes from well-designed FDI policy and high quality infrastructure, both of which complement with FDI in strengthening export capacity, intensity and quality; and (c) human capital and R\&D seems to be more helpful for China to capture spillovers from FDI to export quality.
\end{abstract}

JEL code: F21; F23; O14; O53

Keywords: absorptive capability (AC), foreign direct investment (FDI), manufactured exports (MX)

\footnotetext{
*Yingkai Tang, Business School, Sichuan University, 29 Wangjiang Road, Chengdu, China, 610064. Email: tang@scu.edu.cn. Kevin H. Zhang, Department of Economics, Illinois State University, Normal, IL 61790-4200, USA. Email: khzhang @ilstu.edu. Yingkai Tang would like to acknowledge research support from the National Science Foundation of China (71072066 and 71302183) and the Distinguished Young Scholars Fund of Sichuan University (SKJC201007). The early version of the paper was presented at the conference of "The Chinese Economy: Past, Present and Future" held at Tsinghua University, China, on December 29, 2014. Thanks also go to the conference participants for their helpful comments and Hoa Duong at Illinois State University for her excellent research assistance. Of course, any errors remain our own.
} 


\section{Introduction}

An empirical investigation of role of foreign direct investment (FDI) in a host country's export performance is important, since exports have been viewed as an engine of growth for a long time. There is a widely share view that FDI significantly promotes manufactured exports (MX) of developing economies (Aitken, Hanson \& Harrison, 1997; Harding and Javorcik, 2013). Evidence, however, suggests a different story: only a few of developing economies that are open to FDI experience increases in MX success, most of which is just in labor-intensive products (Greenaway, Sousa \& Wakelin, 2004; UNCTAD, 2002). Does FDI automatically result in export boom in developing countries? If not, what conditions or capabilities, defined as a host country's absorptive capacity (AC), are required as to capture potential benefits from FDI? This paper attempts to work on the questions with the data on the Chinese manufacturing exports.

The case of China seems to be of special significance. China's export boom, from $\$ 18$ billion in 1980 to $\$ 2049$ billion in 2012, was accompanied by substantial FDI inflows (UNCTAD, 2014). While some observers focus the key role of FDI in China's MX success, many others emphasize contributions of AC along with FDI, such as well-designed FDI policy, high quality infrastructure, and large investment in human capital and research and development (R\&D). In particular, it is argued that there is something distinctive and systemic about the FDIMX link which cannot be explained by the familiar framework without domestic AC (UNCTAD, 2002; Zhang, 2006b). Unlike many other developing countries, China seems to build up a strong AC such that it could be able to benefit from FDI in achieving its export miracle.

There is a growing literature on the FDI-export link in China, and these studies have provided useful insights (for example, Blonigen and Ma, 2007; Zhang, 2006a; Swenson, 2008; and Xing, 2012). Research on the role of AC in the FDI-MX nexus, however, has been limited (Girma, 2003; Harding and Javorcik, 2013). In particular, we have not seen any studies on the 
issue with the Chinese evidence. This paper intends to work in this direction and aims at making contributions in the following aspects. First, it develops a theoretical framework of key role of $\mathrm{AC}$ in the FDI-MX linkage, in which MX is influenced by FDI-AC interactions and AC is measured by FDI policy, human capital, R\&D, and infrastructure. Second, it uses an empirical specification that is parsimonious and yet includes both FDI-AC interplay and major MX determinants. Third, MX performance is assessed with not only export volume but also its technological contents. Specially, three MX indicators (capacity, intensity, and quality) are employed in the model to test what impact FDI-AC interactions may have on MX performance.

This paper is structured as follows. After the introduction, a theoretical framework about the role of AC in the FDI-MX link is introduced in the Chinese context and hypotheses then are developed in Section 2. Empirical specification, variable definitions, data, and estimation results are discussed in Section 3. The conclusions are drawn in the last section.

\section{Role of AC in the FDI-MX Link: A Theoretical Framework}

MX performance may be assessed with four indicators grouped along three dimensions, as suggested by UNIDO (2013). Export capacity is measured by the average of MX per capita and MX share in the world; Export intensity is defined as MX share in total exports; and export quality is captured by medium- and high-tech MX share in total MX. China's MX performance and its linkage with FDI are shown in Table 1. In merely 15 years (1995-2010), MX per capita rose 11 times from $\$ 109$ to $\$ 1124$, and China's share in the world increased from 3\% to $14 \%$. Such rapid growth made China to become the largest exporting nation in the world in 2009, and at the same time, MX constituted $96 \%$ of the total exports (UNIDO, 2014). Along the MX volume boom, China's export basket shifted from dominant labor intensive and low-tech products (such as food and textiles) to more medium- and high-tech products (such as machinery 
and electrical equipment), which accounted for $65 \%$ of the total MX in 2010. In particular, the high-tech share in total MX nearly doubled, from $24 \%$ to $41 \%{ }^{1}$ It is widely believed that massive FDI inflows play a crucial role in China's export miracle (UNCTAD, 2002; Zhang, 2006a). China has been the most attractive location for FDI for the past two decades and FDI inflows tripled in 1995-2010, resulting FDI stock of \$588 billion in 2010 (UNCTAD, 2014). The contribution of FDI to China's MX is even larger; more than half of China's MX was generated by foreign-invested enterprises (FIEs), as indicated by Table 1.

\section{Table 1 may be here}

There is a large literature on the role of FDI in host-country exports, theoretical predictions in the context of the AC-FDI-MX link, however, may be summarized along four hypotheses: benefits from FDI on MX depend largely on AC; a country with certain level of AC may reduce negative effects of FDI on MX; FDI may enlarge host export capacity only if the host country has threshold of AC in infrastructure and incentive policies; and a strong AC helps capture spillovers from FDI.

While potential benefits of FDI to host-country MX exist, they do not automatically accrue and tapping the potentials depends on the host country's AC (Girma, 2003; Harrison and Rodriguez-Clare, 2010). AC refers to a country’s ability to identify, assimilate and exploit benefits from FDI, and such the ability reflects multidimensional interaction of many factors, mainly including the country's FDI policy, human capital, research and development (R\&D), and infrastructure quality (Zhang, 2009). Opening up to FDI is only the first step, host countries need to build up dynamic AC based on initial capabilities. For countries with weak industries and

\footnotetext{
${ }^{1}$ Large processing trade and intra-firm trade driven by MNCs inflate China's exports due to imports of intermediate goods/components required to assemble/process for final products. Such data limitations in effect exaggerate somewhat China's overall export sophistication (Rodrik, 2006; Wang and Wei, 2010). Nevertheless, even after taking account of this, China still outperforms the rest of world in structural transformation of manufactured exports (UNCTAD, 2002; UNIDO, 2014).
} 
exports, cheap-labor seeking FDI may well lead only to a short-lived boost in export performance. By plugging into global value chains through FDI, host countries may become suppliers of labor intensive products and components only, without deepening their technologies and upgrading their exports (UNATCD, 2002). To build a more sustainable and dynamic MX base through FDI, host countries have to make great efforts for AC. First, proactive FDI policies are needed may strengthen AC, and such polices include selective liberalization to reconcile efforts to attract FDI with the need to protect particular industries; incentives for FDI conducive to export capacity and upgrading; and incentives for domestic exporting firms in enhancing their export competitiveness (Zhang, 2006a and 2006b; Harrison and Rodriguez-Clare, 2010). Second, AC would be stronger with more human capital and R\&D. Human capital and R\&D increases and productivity of domestic firms through helping technological progress, which enables domestic firms to learn from foreign-invested enterprises and to acquire FDI spillovers (Griffith, Redding \& Reenen, 2003; Harding and Javorcik, 2013). Third, both capability and technology of domestic firms depend critically on the availability and quality of physical infrastructure, ranging from roads and ports to energy and telecommunication. Better infrastructure helps domestic firms gain from FDI (Limao and Venables, 2001). Consequently, our first hypothesis is

H1: What extent a host country's MX may benefit from FDI depends largely on AC.

FDI has negative as well as positive impact on MX, and its net effects depend on the host country's AC. Contributions of FDI to host-country MX may derive from additional capital, technology, and managerial know-how; training for the local workforce; and access to global (Caves, 1996; Girma, Gorg, and Pisu, 2008). It is argued, however, that FDI may lead to negative effects on MX as well: replacing domestic investment for indigenous exporting firms; transferring technologies that are low level or inappropriate for the host country's factor proportions; targeting primarily the host country's domestic market and thus not increase 
exports; inhibiting the expansion of indigenous firms that might become exporters; and not transferring technology but focusing solely on local cheap labor and raw materials (Ram and Zhang, 2002; Zhang, 2006b; Harrison and Rodriguez-Clare, 2010). Whether or not a host country ends up with gains from FDI depends on the country's AC, since it is AC with which the host country could maximize benefits from FDI and minimize FDI costs. In short our hypothesis is as follows:

H2: A country with AC may reduce negative effects of FDI on MX.

While FDI may influence MX in a variety of ways, its direct contribution lies in expanding host-country export capacity, especially in labor-intensive activities (UNCTAD, 2002; and Zhang, 2009). FDI may boost export capacity by following mechanisms: (a) exports through processing and assembling; ${ }^{2}$ (b) exports through converting import-substituting products; (c) exports through market access provided by multinational firms; and (d) exports of local raw materials processing (Zhang and Markusen, 1999). Attracting such export-oriented FDI, however, is itself an intensely competitive business and even the countries that have succeeded would find it difficult to achieve rapid export growth without incentive policies and good infrastructure, or hard to sustain export capacity as their wages rise and market conditions change (Greenaway, Sousa, and Wakelin, 2004). We cover this consideration in the following hypothesis:

H3: FDI may expand host export capacity only if AC is met at threshold of infrastructure. Theories suggest that there are several mechanisms of spillovers from FDI to local firms' exporting activities. Domestic firms may increase their exports by observing the export activities of foreign affiliates ("learning by watching"). The second spillover effect involves market

\footnotetext{
${ }^{2}$ A popular form of this type of export-promoting FDI is export processing zones, in which materials are imported duty free and transformed for exports, with strictly controlled trade with the rest of the host country. Export processing zones allow exploitation of the location-specific assets of a host country while avoiding the restrictions imposed by its trade regime, and providing good infrastructure and offering fiscal incentives (Zhang, 2009).
} 
competition and diffusions of new technologies. By bringing their advanced product-process technology, management, and marketing competence, multinational firms may increase competition in the Chinese markets and force local firms to adopt more efficient methods. The third spillovers are related to the forward and backward linkages between foreign and local firms. If foreign subsidiaries increase their purchase of inputs from local firms, host exports increase (Fosfuri and Saggi, 2002; Kneller and Pisu (2007; Girma, Gorg and Pisu, 2008). While the spillovers can promote China's export quality, capturing spillovers is a long, costly and risky process, as it calls for not only high quality infrastructure and well-designed and effective implement of FDI policy, but also substantial investment in human capital and R\&D. The magnitude and extent of technological benefits from FDI therefore are conditional on AC, especially domestic learning efforts associated with human capital and R\&D (Zhang, 2006a and 2006b). Thus we propose the following hypothesis:

H4: A strong AC helps a host country to capture spillovers from FDI.

\section{Empirical Specifications, Data, and Results}

The preceding discussions suggest an important role of AC in the FDI-MX linkage.

Several empirical specifications can be considered in a study of MXP determinants. The focus of this paper on the interaction of AC and FDI, however, necessitates the use of a model that could capture and isolate the basics of the FDI-AC interplay in $M X P$. Therefore along with $F D I$, the interaction item $(F D I \times A C)$ may be treated as an additional factor in the conventional framework of $M X P$ determination, resulting in the following equation for China's region $i$ in year $t$ :

$$
M X P_{i t}=\alpha_{0}+\beta \boldsymbol{Z}+\gamma F D I_{i t}+\delta(F D I \times A C)_{i t}+\theta_{i}+\mu_{t}+\varepsilon_{i t}
$$

where $\alpha_{0}$ is the constant term and $\varepsilon_{i t}$ as stochastic component. $\theta_{i}$ and $\mu_{t}$ are unobserved regionspecific and time-specific effects, respectively. $\boldsymbol{Z}$ is a vector of conventional MXP determinants, 
including physical capital $(K)$, human capital $(H K)$, infrastructure $(I N F R)$, and government industrial policy (POLICY), as suggested in the literature (Fugazza, 2004; UNCTAD, 2002). ${ }^{3}$

The rationale for each independent variable is discussed in the previous section except physical capital $(K) .{ }^{4}$ Therefore, equation (1) may read as:

$$
\begin{aligned}
M X P_{i t}=\alpha_{0} & +\alpha_{1} K_{i t}+\alpha_{2} H K_{i t}+\alpha_{3} R \& D_{i t}+\alpha_{4} I_{N F R_{i t}}+\alpha_{5} P_{O L I C Y_{i t}} \\
& +\alpha_{6} F_{i t}+\alpha_{7}\left(F D I_{i t} \times A C_{i t}\right)+\theta_{i}+\mu_{t}+\varepsilon_{i t}
\end{aligned}
$$

The dependent variable of $M X P$ is measured by three indices: capacity, intensity and quality. Export capacity is captured by the average of MX per capita (MXPC) and MX share in the world (MXWS). Export intensity is reflected by MX share in total exports (MX/X). Export quality is proxied by medium- and high-tech MX shares in total MX (MXQ). ${ }^{5}$ Data on 21 manufacturing sectors for 31 regions in 8 years (2005-2012) are collected from China Industry Economy Statistical Yearbook 2006-2012 (NBSC, 2006-2013) and China Statistical Yearbook 2012 (NBSC, 2006-2013). ${ }^{6}$ The values for each of the four indicators (MXPC, MXWS, MX/X, and MXQ) are standardized for each region, ranging from zero (worst performer) to one (best performer). The formula used in the standardized procedure is

$$
I_{i j t}=\frac{X_{i j t}-\operatorname{Min}_{j}\left(X_{i j t}\right)}{\operatorname{Max}_{j}\left(X_{i j t}\right)-\operatorname{Min}_{j}\left(X_{i j t}\right)}, \quad i=1,2,3,4 ; j=1, \ldots, 31 ; t=2005, \ldots, 2012
$$

\footnotetext{
${ }^{3}$ It should be noted that other $M X P$ determinants may exist but are excluded from the specification. This model, therefore, should not be treated as an exhaustive $M X P$ study of China but, rather, as a narrowly focused investigation of the AC-FDI link. Other considerations for the specification include data availability and characteristics of crossprovince (within China, rather than cross-country) estimations.

${ }^{4}$ As the stock of physical capital $(K)$ increases, a nation/region experiences capital deepening that makes more tools, structures, and equipment available to each worker. Capital deepening provides for a more productive labor force and thus enhances industrial upgrading.

${ }^{5}$ The technologic classification of the manufacturing sectors is based on OECD standard and global technological intensity (OECD, 2001).The four categories of 21 manufacturing sectors in China are as follows. (a) High-tech industries: pharmaceuticals, transport equipment, and electronic communications and computers; (b) Medium-hightech: chemicals, chemical fibers, general machinery, special machinery, electrical equipment and machinery, and scientific instruments and office machinery; (c) Medium-low-tech: petroleum refining, non-metallic mineral products, ferrous metals, non-ferrous metals, and metal products; and (d) low-tech: food processing, food manufacturing, beverage, tobacco, textiles, clothing, and paper.

${ }^{6}$ The period is picked up totally based on data availability and consistence of all variables used in the work.
} 
where $X_{i j t}$ is value of the indicator $(I) i(i=1$ to 4$)$ of the region $j(j=1$ to 31$)$ in year $\mathrm{t}(\mathrm{t}=2005$ to 2012), Min is the smallest value in the sample and Max the largest.

All independent variables in equation (3) are measured in a way similar to that used in the literature. Physical capital $(K)$ is proxied by the ratio of physical capital stock to GDP, in which we define the capital stock in year $t\left(K_{t}\right)$ and initial capital stock $\left(K_{0}\right)$ in the following way

$$
K_{t}=K_{t-1}+\frac{I_{t}-D_{t}}{P_{t}}, \text { and } K_{0}=\frac{I_{0}}{\delta+g}
$$

where $I_{t}$ is investment in year t, $D_{t}$ is depreciation, $P_{t}$ is price level, $I_{0}$ is initial real investment, $\delta$ is the rate of depreciation and $g$ is the growth rate in real investment (Ang and Madsen, 2011; Zhang and Zhang, 2003). The share of tertiary enrollments in technical subjects in total population is taken as a proxy for human capital $(H K)$. Research and Development $(R \& D)$ is captured by the number of patents application granted. ${ }^{7}$ Infrastructure (INFR) is proxied by an index that is computed as a weighted average the three standardized indicators: length of railways in operation per one hundred square kilometers, length of highways per one hundred square kilometers, and capacity of mobile telephone exchanges per one thousand people. ${ }^{8}$ The data on $K, H K, R \& D$, and INFR are taken and computed from China Statistical Yearbook 20062013 (NBSC, 2006-2013). FDI policy (POLICY) is a dummy variable, taking value one for coastal regions and zero for inland regions, which reflects the fact that China's central government FDI policies and strategies resulted in obvious advantages of coastal regions over inland regions. ${ }^{9}$ Data for all independent variables are taken from China Statistical Yearbook 2006-2012 (NBSC, 2006-2012).

\footnotetext{
${ }^{7}$ R\&D expenditures may be a better indicator for $R D$ than the number of patents application granted, but the data on the former are unavailable for all years except 2011.

${ }^{8}$ The formula used here for standardized indicators is same as that for four indices of MXP.

${ }^{9}$ China has 31 administrative units of regions, including 22 provinces, 5 autonomous regions, and 4 municipalities. Taiwan, Hong Kong, and Macao are not included in the sample. The coastal area (also called Eastern China) comprises 11 regions: Beijing, Tianjin, Hebei, Liaoning, Shanghai, Jiangsu, Zhejiang, Fujian, Shandong,
} 
The FDI variable is constructed in two forms: share of manufactured output by foreigninvested enterprises (FIEs) in total (FIEYS) in a region and ratio of FDI stock to GDP (FDIS) in a region. The use of alternative measures of FDI serves for robustness checks in the following section. The data on FIEYS are calculated from China Industrial Economy and Statistical Yearbook 2006-2012 (NBSC, 2006-2013), and the data on FDIS are constructed based on China Statistical Yearbook 2006-2012 (NBSC, 2006-2013).

The AC variable is proxied by its four determinants (HK, $R \& D, I N F R$, and POLICY), each of which is based on different reasoning. While all of three aspects of MXP (export capacity, intensity, and quality) are influenced by four $A C$ measures along with FDI, $(F D I \times H K)$ and $(F D I \times R \& D)$ seem to have larger effects on export quality and intensity, and the impact of $(F D I \times I N F R)$ and $(F D I \times P O L I C Y)$ on export capacity are assumed to be greater.

Table 2 reports panel estimates of China's MXP determinations, with focus on the role of AC in effects of FDI on MX. Due to high correlation between the two FDI variables, FIEYS and FDIS are not introduced simultaneously in the regressions but are entered separately. All regressions are conducted with fixed effects because assumptions for OLS pooling and random effects are rejected. ${ }^{10}$ In general, the regression estimates are reasonable and plausible, and the explanatory power is fairly good. Adjusted $R^{2}$ of regressions is high in all cases (0.57-0.86), indicating that most of the variance in all three MXP indicators of Table 2 can be accounted for with the independent variables.

Table 2 may be here

Guangdong and Hainan. The inland area (Central and Western China) is composed of the remaining 20 regions: Shanxi, Jilin, Heilongjiang, Anhui, Jiangxi, Henan, Hubei, Hunan, Inner Mongolia, Guangxi, Chongqing, Sichuan, Guizhou, Yunnan, Tibet, Shaanxi, Gansu, Qinghai, Ningxia and Xinjiang.

10 The likelihood ratio and Lagrange multiplier statistics and Hausman test are significant at the 1\% level, indicating that the OLS pooling and random effect models are not valid (Baltagi, 1995). 
Some points are discerned easily from Table 2. First, contributions of FDI to MXP are larger when FDI works with AC together than FDI alone. In each case of three MX indicators, coefficients of FDI-AC interactive variables are either more significant or greater in value than those of FDI variable alone. Especially in the intensity- and quality-models, the coefficients of FDIS and FIES are not significant at all but those of most interactive items are significant.

Second, FDI policy and infrastructure seem to be more important to benefits from FDI to export capacity, while human capital and R\&D are conditions primarily to promoting effects of FDI on export quality and intensity. Third, FDI policy and infrastructure are more important elements of China's overall AC than human capital and R\&D. The coefficients of $(F D I \times P O L I C Y)$ and $(F D I \times I N F R)$ are significantly positive in all cases, suggesting a key role of FDI policy and infrastructure in capturing benefits from FDI. Fourth, conventional MX determinants show a different pattern in affecting export performance. Physical capital (K) seems to enhance all three dimensions (export capacity, intensity, and quality); so are FDI policy and infrastructure alone. The impact of human capital and R\&D alone on MXP seems to be limited, although they could, along with FDI, strengthen export quality and intensity. Last and once again, FDI alone seems not to have significant effects on China's manufactured exports, especially on export quality and intensity.

The finding from the estimates is consistent with theoretical predictions and evidence in the literature. China's export miracle indeed benefits largely from FDI. Such large benefits from FDI, however, are captured on condition that China has done very well in FDI policy, infrastructure, human capital, and R\&D (UNIDO, 2013). Without the strong AC, China's success in MX would not be possible even with large FDI inflows. China's FDI policy is not only well designed but also implemented effectively due to China's unique bargaining power over multinational corporations (UNCTAD, 2002; Zhang, 2006a). With large investment in 
modern infrastructure such as railways, highways, seaports, airports, and telecommunications, China has become the only developing country that possesses high quality infrastructure comparable to developed economies, which drives substantial growth in manufactured export capacity, intensity, and quality (Zhang, 2006a; Swenson, 2008).

Several tests and sensitivity checks must be conducted for robustness and endogeneity. Sensitivity checks with alternative measures of dependent variable (MXP) and independent variables (FDI and FDI $\times$ AC) are reported in Table 2 as well. Three different indicators of MXP (export capacity, intensity, and quality) and two different measures of FDI and thereby (FDI $\times$ AC) are employed in regressions. The estimate results reported in Table 2 are similar in large and none of the estimation results is significantly affected by these alternative measures of MXP, FDI and (FDI $\times A C)$, implying that the observed results seem not to depend on specific measures used to quantify dependent and independent variables.

Another sensitivity checks are conducted with the instrumental available (IV) technique to deal with the possible endogeneity bias. The two-year lagged values of FDIS and FIES are used as instrumental variables due to their high correlation with current values of the variables in Table 2 (Lileeva and Trefler, 2010). IV estimations with alternative measures of FDI and $(\mathrm{FDI} \times \mathrm{AC})$ are presented in Table 3 . The coefficients of FDI and (FDI $\times$ AC) variables remain positive and are similar qualitatively and quantitatively with those in Table 2 , suggesting robust results and little endogeneity bias in our regressions in Table 2. The Wu-Hausman test statistics (Maddala and Lahiri, 2009) cannot reject the hypothesis that independent variables to be exogenously determined and the main estimates of Table 2 seem to be unlikely to suffer from endogeneity bias.

Table 3 may be here 


\section{Concluding Observations}

The objective of this study is to investigate the role of absorptive capacity in effects of FDI on host-country manufactured exports. The paper is motivated by several considerations as follows. Manufactured exports are important to economic growth in developing countries and FDI is expected to promote host-country exports. Benefits from FDI seem not automatically appear but depend on a host-country's absorptive capacity, which is associated with the country's FDI policy, human capital, R\&D, and infrastructure quality. While there are many studies on the FDI-exports in the literature, work on the role of absorptive capacity in effects of FDI on host exports has been limited. To close the gap in the literature, we take China as a case study by working with a panel dataset that contains 21 manufacturing sectors for 31 regions covering 8 years from 2005 to 2012. MX performance is assessed with three indicator, export capacity, export intensity, and export quality, and the role of absorptive capacity is measured by interaction between FDI and four AC determinants.

Subject to the caveats appropriate for such panel studies, the basic finding is summarized as follows. First, absorptive capacity is necessary condition for China to benefit from FDI in MXP, and contributions of FDI alone to MXP are limited. Second, China's strong absorptive capacity largely comes from well-designed FDI policy and high quality infrastructure, both of which complement with FDI in strengthening China's export capacity, intensity and quality. Third, investment in human capital and R\&D seems to be more helpful for China to capture spillovers from FDI to export quality. Last, FDI still remains as a catalyst of and irreplaceable to China's MX success. Working together with domestic absorptive capacity, FDI made a crucial contribution to China's manufactured export development. 
Table 1 Manufactured Exports and Role of FDI in China: 1995-2010

\begin{tabular}{|c|c|c|c|c|}
\hline & 1995 & 2000 & 2005 & 2010 \\
\hline \multicolumn{5}{|l|}{ Manufactured Export Performance } \\
\hline \multicolumn{5}{|l|}{ Export Capacity } \\
\hline MX per capita (US\$) & 108.90 & 179.90 & 550.40 & 1123.60 \\
\hline MX share in the world $(\%)$ & 3.43 & 4.71 & 9.32 & 14.06 \\
\hline \multicolumn{5}{|l|}{ Export Intensity } \\
\hline MX share in total exports $(\%)$ & 88.81 & 91.66 & 94.84 & 96.25 \\
\hline \multicolumn{5}{|l|}{ Export Quality } \\
\hline HMT-MX share in total MX (\%) & 43.11 & 53.18 & 63.48 & 64.93 \\
\hline HT-MX share in total MX $(\%)$ & 24.08 & 30.28 & 41.97 & 41.49 \\
\hline \multicolumn{5}{|c|}{ Role of FDI in the Manufactured Exports } \\
\hline FDI flows (billions of US\$) & 37.52 & 40.72 & 72.41 & 114.73 \\
\hline FDI stock (billions of US\$) & 101.01 & 193.35 & 272.09 & 587.82 \\
\hline MX by FIEs (billions of US\$) & 46.88 & 119.44 & 444.21 & 862.31 \\
\hline FIEs share in total MX $(\%)$ & 31.51 & 47.93 & 58.29 & 54.65 \\
\hline FIEs share in total MHT-MX $(\%)$ & 31.20 & 42.11 & 49.80 & 57.92 \\
\hline FIEs share in total HT-MX $(\%)$ & 48.02 & 71.72 & 82.38 & 78.53 \\
\hline \multicolumn{5}{|c|}{$\begin{array}{l}\text { Notes: MX = manufactured exports; MHT = medium- and high-tech; HT = high-tech; and FIEs = foreign-invested } \\
\text { enterprises. } \\
\text { Source: Computed based on United Nations Industrial Statistics Database (UNIDO, 2013), Statistics on FDI in } \\
\text { China } 2014 \text { (Ministry of Commerce of China, 2014), China Statistics Yearbook } 2012 \text { (NBSC, 2012), Xing (2012), }\end{array}$} \\
\hline
\end{tabular}


Table 2 Panel and Alternative Estimations of FDI-AC-MXP Linkage: 2005-2012

\begin{tabular}{|c|c|c|c|c|c|c|}
\hline \multirow{2}{*}{$K$} & \multicolumn{2}{|c|}{ Capacity } & \multicolumn{2}{|c|}{ Intensity } & \multicolumn{2}{|c|}{ Quality } \\
\hline & $0.173 * *$ & $0.160 * *$ & $0.037 * *$ & $0.041 *$ & $0.084 *$ & $0.072 * *$ \\
\hline & $(2.389)$ & $(2.501)$ & $(2.287)$ & $(1.802)$ & $(1.756)$ & $(2.527)$ \\
\hline \multirow[t]{2}{*}{$H K$} & $0.321 *$ & 0.267 & $0.250 *$ & $0.302 *$ & $0.098^{*}$ & $0.102 *$ \\
\hline & $(1.847)$ & $(0.985)$ & (1.817) & $(1.711)$ & $(1.835)$ & (1.814) \\
\hline \multirow[t]{2}{*}{$R D$} & 0.191 & 0.233 & 0.009 & $0.015^{*}$ & $0.182 *$ & 0.201 \\
\hline & $(0.367)$ & $(0.450)$ & $(1.012)$ & $(1.708)$ & $(1.756)$ & (1.314) \\
\hline \multirow[t]{2}{*}{$I N F R$} & $0.301 * *$ & $0.250 * * *$ & $0.102 * *$ & $0.082 * *$ & $0.139 * *$ & $0.157 * *$ \\
\hline & $(2.701)$ & (3.604) & $(2.336)$ & $(2.517)$ & $(2.668)$ & $(2.433)$ \\
\hline \multirow[t]{2}{*}{ POLICY } & $0.451 * * *$ & $0.399 * * *$ & $0.304 * * *$ & $0.299 * * *$ & $0.287 * * *$ & $0.305 * * *$ \\
\hline & (5.121) & (6.382) & (4.005) & (3.877) & (4.110) & (4.207) \\
\hline \multirow[t]{2}{*}{ FDIS } & $0.285^{*}$ & & 0.187 & & 0.213 & \\
\hline & $(1.750)$ & & $(1.493)$ & & (1.081) & \\
\hline \multirow[t]{2}{*}{$F D I S \times H K$} & 0.302 & & $0.185 * *$ & & $0.287 * * *$ & \\
\hline & (1.508) & & $(2.280)$ & & (3.667) & \\
\hline \multirow[t]{2}{*}{$F D I S \times R D$} & 0.354 & & $0.202 *$ & & $0.297 * *$ & \\
\hline & $(0.557)$ & & $(1.805)$ & & $(2.487)$ & \\
\hline \multirow[t]{2}{*}{$F D I S \times I N F R$} & $0.354 * * *$ & & $0.202 * * *$ & & $0.297 * *$ & \\
\hline & (5.178) & & (3.934) & & $(2.567)$ & \\
\hline \multirow[t]{2}{*}{$F D I S \times P O L I C Y$} & $0.658 * * *$ & & $0.358 * *$ & & $0.320 * *$ & \\
\hline & (6.216) & & $(2.501)$ & & $(2.712)$ & \\
\hline \multirow[t]{2}{*}{ FIES } & & $0.301 *$ & & 0.154 & & 0.287 \\
\hline & & $(1.885)$ & & $(1.011)$ & & $(1.605)$ \\
\hline \multirow[t]{2}{*}{$F I E S \times H K$} & & 0.225 & & $0.147 *$ & & $0.302 * *$ \\
\hline & & (1.114) & & $(1.771)$ & & (2.302) \\
\hline \multirow[t]{2}{*}{$F I E S \times R D$} & & 0.225 & & 0.202 & & $0.305 * * *$ \\
\hline & & $(0.408)$ & & (1.511) & & (3.970) \\
\hline \multirow[t]{2}{*}{$F D I S \times I N F R$} & & $0.410 * * *$ & & $0.227 * * *$ & & $0.356^{* *}$ \\
\hline & & (4.224) & & (4.187) & & (2.611) \\
\hline \multirow[t]{2}{*}{$F I E S \times P O L I C Y$} & & $0.597 * * *$ & & $0.411 * *$ & & $0.297 * *$ \\
\hline & & (6.228) & & $(2.707)$ & & $(2.663)$ \\
\hline Reg. Dummy & Yes & Yes & Yes & Yes & Yes & Yes \\
\hline Year Dummy & Yes & Yes & Yes & Yes & Yes & Yes \\
\hline Adj. $R^{2}$ & 0.837 & 0.829 & 0.723 & 0.708 & 0.815 & 0.783 \\
\hline Observations & 248 & 248 & 248 & 248 & 248 & 248 \\
\hline
\end{tabular}

Notes: Constant terms are omitted (but available upon request) to save space. Figures in parentheses are $t$-statistics. The asterisks *,**, and $* * *$ indicate significant levels at $10 \%, 5 \%$, and $1 \%$, respectively. 
Table A1 Instrument Variable Estimations of FDI-AC-MXP: 2005-2012

\begin{tabular}{|c|c|c|c|}
\hline & Capacity & Intensity & Quality \\
\hline \multirow[t]{2}{*}{$F D I S$} & $0.201 *$ & 0.112 & $0.266^{*}$ \\
\hline & $(1.771)$ & (1.002) & $(1.821)$ \\
\hline \multirow[t]{2}{*}{$F D I S \times H K$} & 0.401 & $0.145^{*}$ & $0.313 * *$ \\
\hline & $(1.448)$ & (1.799) & $(2.556)$ \\
\hline \multirow[t]{2}{*}{$F D I S \times R D$} & 0.244 & $0.123 *$ & $0.310^{*}$ \\
\hline & $(0.701)$ & $(1.751)$ & $(2.002)$ \\
\hline \multirow[t]{2}{*}{$F D I S \times I N F R$} & $0.412 * * *$ & $0.197 * * *$ & $0.335^{* *}$ \\
\hline & $(5.558)$ & (4.022) & $(2.815)$ \\
\hline \multirow[t]{2}{*}{$F D I S \times P O L I C Y$} & $0.701 * * *$ & $0.322 * *$ & $0.421 * *$ \\
\hline & $(5.895)$ & $(2.662)$ & $(2.778)$ \\
\hline \multirow[t]{2}{*}{ FIES } & $0.198 *$ & 0.175 & 0.302 \\
\hline & $(1.771)$ & $(0.984)$ & $(1.501)$ \\
\hline \multirow[t]{2}{*}{$F I E S \times H K$} & 0.311 & 0.202 & $0.388 * *$ \\
\hline & $(0.799)$ & $(1.525)$ & $(2.551)$ \\
\hline \multirow[t]{2}{*}{$F I E S \times R D$} & 0.338 & $0.326^{*}$ & $0.368^{*}$ \\
\hline & (1.556) & (1.884) & $(2.711)$ \\
\hline \multirow[t]{2}{*}{$F D I S \times I N F R$} & $0.510 * * *$ & $0.199 * *$ & $0.401 * *$ \\
\hline & (4.840) & $(2.665)$ & $(2.443)$ \\
\hline \multirow[t]{2}{*}{$F I E S \times P O L I C Y$} & $0.662 * * *$ & $0.365 * *$ & $0.388 * *$ \\
\hline & (6.101) & $(2.557)$ & $(2.455)$ \\
\hline
\end{tabular}

Notes: same as those in Table 2. Estimates for other variables except FDI and four absorptive capacity (AC) measures are omitted (but available upon request) to save space. Data on FDI and AC variables in 2003 and 2004 are available and thus the sample size in the estimations with two-year lagged variables does not decrease. 


\section{References}

Aitken, B., Hanson G., \& Harrison A. (1997). Spillovers, foreign investment, and export behavior. Journal of International Economics, 43(1-2), 103-132.

Ang, J. B. \& Madsen, J. B. (2011). Can second-generation endogenous growth models explain productivity trends and knowledge production in the Asian miracle economies? Review of Economics and Statistics, 93, 1360-73.

Baltagi, B. (1995). Econometric Analysis of Panel Data. Chichester: Wiley.

Blonigen, B. \& Ma A. (2007). Please pass the catch-up: the relative performance of Chinese and foreign firms in Chinese exports. NBER Working Paper 13379.

Caves, R. (1996). Multinational Enterprises and Economic Analysis. (2 ${ }^{\text {nd }}$ ed). Cambridge, MA: Cambridge University Press.

Fosfuri, A. and Saggi, K. (2002). Foreign direct investment and spillovers through workers' mobility. Journal of International Economics, 53(1), 205-222.

Fugazza, M. (2004), Export performance and its determinants: supply and demand constraints. UNCTAD Policy Issue in International Trade and Commodities Studies Series N. 26.

Girma, S. (2003). Absorptive capacity and productivity spillovers from FDI: a threshold regression analysis. Working paper 25/2003, European Economy Group.

Girma, S., Gorg, H. \& Pisu, M. (2008). Exporting, linkages and productivity spillovers from foreign direct investment. Canadian Journal of Economics, 41(1), 320-340.

Greenaway, D., Sousa, N. \& Wakelin K. (2004). Does domestic firms learn to export from multinationals? European Journal of Political Economy, 20, 1027-1043.

Griffith, R., S. Redding, \& J. V. Reenen (2003), "R\&D and absorptive capacity: theory and empirical evidence," Scandinavian Journal of Economics, 105, 99-118.

Harding, T. \& Javorcik, B. S. (2013). FDI and export upgrading. Review of Economics and Statistics, forthcoming.

Harrison, A. \& A. Rodriguez-Clare (2010), "Trade, foreign investment, and industrial policy for developing countries," Chapter 63, The Handbook of Development Economics, Vol. 5, 40394214.

Kneller, R. \& M. Pisu (2007), “Industrial linkages and export spillovers from FDI,” World Economy, 30(1), 105-134.

Levine, R. \& D. Renelt (1992), "A sensitivity analysis of cross-country growth regressions," American Economic Review, 82 (4), 942-963. 
Lileeva, A, \& Trefler, D. (2010), Improved access to foreign markets raises plant-level productivity ... for some plants. Quarterly Journal of Economics, 125 (3),1051-1099.

Limao, N. \& Venables, T. (2001). Infrastructure, geographical disadvantage, transport costs and trade. World Bank Economic Review, 15(3), 451-479.

Maddala, G. S. \& Lahiri, K. (2009). Introduction to Econometrics. (4 ${ }^{\text {th }}$ ed.). Hoboken, NJ: Wiley.

Ministry of Commerce of China (MCC) (2013). Statistics on FDI in China 2012. Beijing: Ministry of Commerce of China.

National Bureau of Statistical of China (NBSC) (2004-2013). China Industry Economy Statistical Yearbook 2004-2012. Beijing, China: China Statistics Press.

NBSC (2004-2013). China Statistical Yearbook 2004-2012. Beijing, China: China Statistics Press.

Organization for Economic Co-operation and Development (OECD) (2001). OECD Science, Technology and Industry Scoreboard: Toward a Knowledge-Based Economy. Paris: OECD.

Ram, R. \& Zhang, K. (2002). Foreign direct investment and economic growth: evidence from cross-country data for the 1990s. Economic Development and Cultural Change, 51(1), 205-215.

Rodrik, D (2006). What's so special about China's exports? China \& World Economy, 14(5), 119.

Schott, P. (2008). The relative sophistication of Chinese exports. Economic Policy, 23, 5-49.

Swenson, D. L. (2008). Multinationals and the creation of Chinese trade linkages. Canadian Journal of Economics, 41(2), 596-618.

UNCTAD (2002). World Investment Report 2002: Transnational Corporations and Export Competitiveness. New York: United Nations.

UNCTAD (2014). UNCTADSTAT Database. New York: United Nations.

United Nations Industrial Development Organization (UNIDO) (2013). Industrial Competitiveness of Nation: Looking back, forging ahead. Vienna: United Nations.

UNIDO (2014). United Nations Industrial Statistics Database. Vienna: United Nations.

Wang, Z. \& Wei, S. J. (2010). What accounts for the rising sophistication of China's exports? In Feenstra \& Wei (ed.). China's Growing Role in World Trade, University of Chicago Press.

Xing, Y. (2012). The People's Republic of China's high-tech exports: myth and reality. Asian Development Bank Working Paper No. 357.

Zhang, K. H. (2006a). The role of FDI in China's export performance. In Zhang (ed.). China as the World Factory (pp. 139-155). Routledge, Taylor \& Francis Group plc., London. 
Zhang, K. H. (2006b). Foreign direct investment in China. Canadian Foreign Policy, 13(2), 3550 .

Zhang, K. H. (2009). FDI and export performance. In Reinert and Rajan (eds.), The Princeton Encyclopedia of the World Economy (pp. 454-456). Princeton: Princeton University Press,.

Zhang, K. H. \& Markusen J. R. (1999). Vertical multinationals and host-country characteristics. Journal of Development Economics, 59, 233-252.

Zhang, X. \& Zhang K. H. (2003). How does globalization affect regional inequality within a developing country? Evidence from China. Journal of Development Studies, 39(4), 47-67. 